\title{
The Role of Social Risk Management in Development: A World Bank View
}

\author{
Robert Holzmann and Valerie Kozel
}

\begin{abstract}
1 Introduction
Social protection and labour policies are important for sustainable and equitable economic growth, contribute in fundamental ways to human development, and are essential for poverty reduction. There is broad agreement across countries, international institutions, and the wider development community that social protection is critical to achieving international development objectives, including the Millennium Development Goals (World Bank 2007).

The World Bank has been engaged in social protection and labour activities for more than two decades, providing strategic advice and support to countries throughout the world. The conceptual foundations of the Bank's social protection strategy are set forth in Social Protection Strategy: From Safety Net to Springboard (World Bank 2001), and have been applied and deepened in recent World Development Reports (WDRs) and other major Bank publications. The strategy is driven by three fundamental development objectives - good jobs, greater security, and enhanced equity - and is innovative in placing particular emphasis on risk and risk management as a complement to social protection's more traditional emphasis on equity and basic needs.
\end{abstract}

The Bank's work on risk and vulnerability is underpinned by the Social Risk Management (SRM) framework, which has been discussed widely in global forums and is used extensively outside as well as within the Bank. This article describes the SRM framework and its key contributions to the global development debate. To this end, Section 2 describes the rationale behind SRM thinking and its key contributions: first, that risk and access to risk management instruments matter in fundamental ways for development, and second, that spending on social protection is not luxury consumption but instead is a necessary investment for achieving sustainable and equitable economic growth. Section 3 describes the key elements of the SRM framework. Section 4 then outlines the major ways that SRM has helped the Bank in rethinking social protection programmes, stimulated a more dynamic view on poverty, and fostered concerns with vulnerable groups. The SRM framework has been further developed and refined over time: Section 5 describes new challenges and work in progress, e.g. towards a more robust and operational definition of vulnerability, the importance of back-up plans in risk management, exploring empirical links between risk and growth. $A$ few concluding remarks stand at the end.

\section{Risk and development}

Risk matters for human and economic development - in many settings, risk and the absence of adequate risk management instruments are together one of the main causes of chronic as well as transitory poverty. Consider the following simple schema (Table 1): uninsured risk affects behaviour ex ante - poor and marginalised groups may adopt various measures to protect themselves in the event of a shock, including avoiding potentially risky but profitable economic activities. Thus risk avoidance works to reduce future welfare levels. There is a further welfare loss when a shock actually occurs; and shocks also affect behaviour ex post (Dercon 2005).

Men, women and children in low-income countries face many risks, some unique to themselves and their families (idiosyncratic) and others shared more widely (covariate). Idiosyncratic shocks are closely linked to human development. Consider the case of 'health 


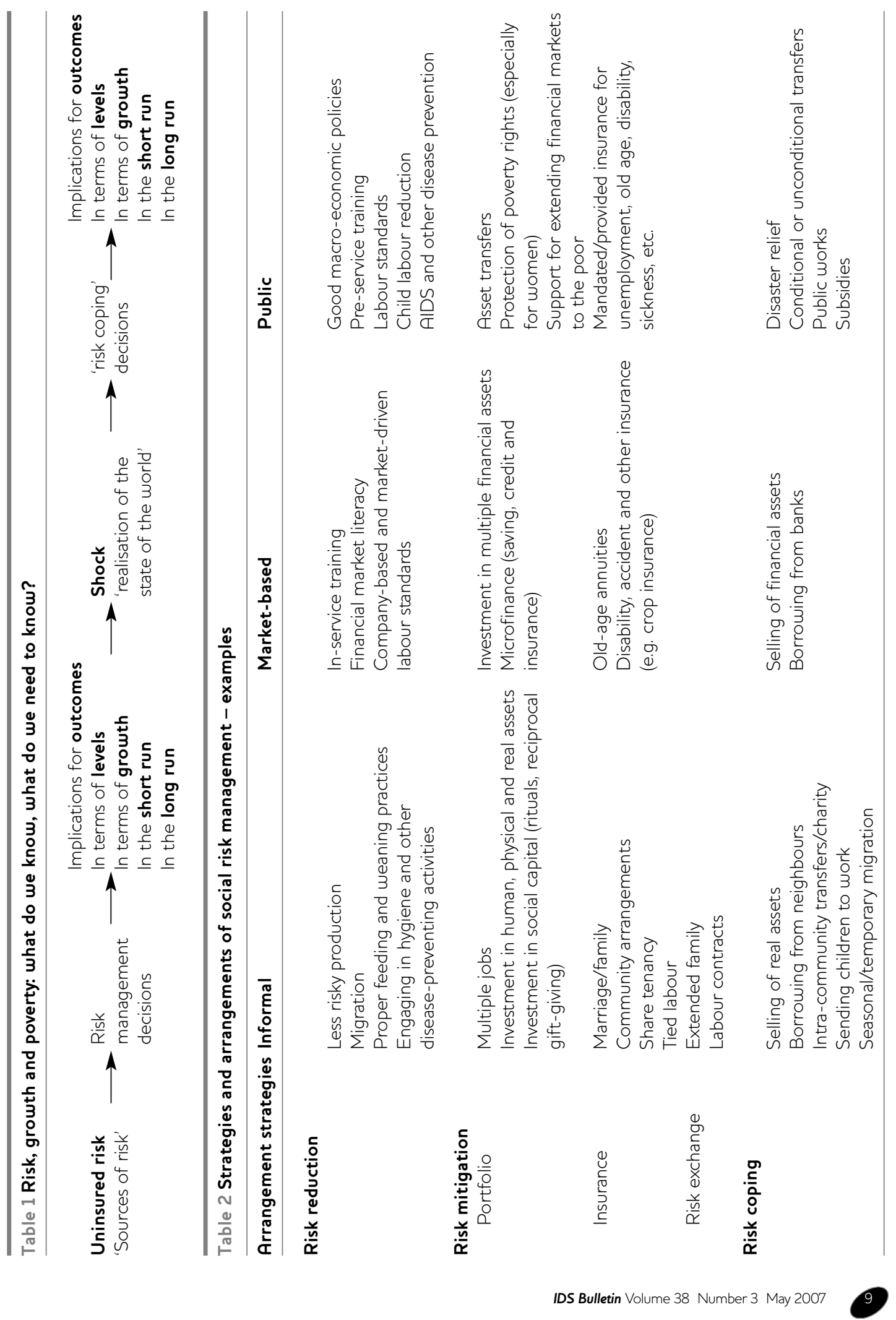


capital'. Ideally, everybody is born with a full health capital that degrades slowly but progressively over time. The poorest, however, already show the marks of shocks that hit their mother prior to birth. After birth, further shocks to income and nutrition exhibit the well-documented effects of stunting, which can include permanent effects on cognition and learning Health shocks occur throughout an individual's lifetime; if not properly treated these lead to an accelerated degradation of health capital with concomitant impacts on skill acquisition and income for the individual, as well as effects on the next generation.

Health is only one example. Many other shocks, such as droughts and floods, price fluctuations and inflation, wars and civil strife, but also disability and unemployment, impact on individual behaviour and investment decisions. Lack of access to instruments designed to deal with these risks and help individuals and households smooth consumption can lead to income-smoothing through sales of assets, or the adoption of less profitable production technologies. If the shocks are very strong, or repeated or bunched, individuals and their families may be trapped permanently at low levels of wellbeing, or pushed even deeper into destitution, from which there may be no chance of recovery.

There is a growing body of empirical evidence on the links between risk, shocks and wellbeing in lowincome settings. ${ }^{1}$ Although challenges remain on the policy front, the conclusions for human and economic development are clear.

First, assisting individuals, households and communities to better manage risks is not a luxury that only rich countries can afford. On the contrary, providing appropriate risk management instruments, including social protection, is an essential investment to ensure that all people, and in particular the poorest, move permanently out of poverty. Everybody is vulnerable to poverty - the shock(s) only need to be strong enough. Good risk management contributes to efficiency.

Second, besides efficiency, the access to or provision of risk management instruments has important equity effects. The value of risk management instruments is typically much more important for the poor, as their income equivalent in incomplete risk markets tends to be much higher. As a result, the provision of risk management instruments leads to redistribution mainly towards the poor, and hence more equal welfare position than measured by mere monetary income inequality (Holzmann 1990).

Last but not least, the equity effects of better risk management suggest having in turn, major efficiency effects for development. Assisting equality of opportunity typically helps the most marginalised in a society, with important effects on development outcomes (World Bank 2004). Assisting equality in outcome can - within limits - encourage risk taking, a crucial element for development and economic growth. On the other hand, establishing full equality in outcome threatens to eliminate any effort, as any gains from risk-taking would be socialised.

\section{The SRM framework - key elements}

The SRM framework is based on two important principles: (1) the poor are typically most exposed to diverse risks, ranging from natural to man-made risks and from health to political risks, and (2) the poor have the fewest instruments to deal with these risks, e.g. access to government-provided income support and market-based instruments like insurance. These principles have important consequences: (a) the poor are the most vulnerable in society because shocks are likely to have the strongest welfare consequences for them; and (b) high levels of vulnerability cause the poor to be risk averse and thus unable or unwilling to engage in higher risk/higher return activities. Access to better instruments to manage risk - either ex ante or ex post - would allow the poor to take more (potentially high reward) risks and thus provide them with an opportunity to move gradually out of poverty. Hence providing risk management instruments to individuals, and in particular to the poor, can be viewed as both an end and a means to development.

The main elements of the SRM framework are derived by introducing the notion of asymmetric information in a world of diverse risks, in a more explicit way than has been done previously. Compared with an ideal world (a la Arrow-Debreu), this has several consequences for managing risks; most importantly:

1 The sources and the forms of risk matter, e.g. whether a particular risk is idiosyncratic or covariant, or whether risks are bunched or repeated. Informal or market-based risk management instruments are well suited for 
addressing idiosyncratic risk; in contrast, covariant risks often call for greater government involvement.

2 Since risk is not necessarily exogenous, risk management can take place at different moments - both before and after a shock occurs. The goal of ex ante measures is to prevent the risk from occurring, or, if this cannot be done, to mitigate the effects of the risk through portfolio diversification, insurance, or risk exchange. Coping strategies are applied after a shock has occurred (that is, after the risk is realised) and, if these are not accompanied by adequate ex ante measures, this residual strategy can have negative long-term consequences for the poor.

3 Because private insurance markets tend not to emerge or to break down when there is asymmetric information, there are three main institutional arrangements for dealing with risk: informal (family or community-based), marketbased and publicly-provided mechanisms.

4 There are multiple suppliers of risk management instruments (including individuals, households, communities, NGOs, market institutions, government, international organisations and the world community at large) and many distinct types of consumers (e.g. workers in the urban formal and informal sectors, agricultural households, the elderly, widows with young children).

Table 2 presents the SRM framework in matrix form, providing examples of risk management instruments through the interaction of risk strategies and risk arrangements. Many of the policies and programmes described in the cells of the matrix, such as sound macroeconomic policies and well-functioning financial markets, lie outside social protection. Moreover, the specific instruments included in the matrix will vary by country and setting. But the framework and the underlying real-life examples highlight, inter alia, (1) the importance of informal arrangements - in the developing world, family and community remain the first line of defence against many types of risk; (2) the importance of marketbased instruments that provide inflation-proof money and access to simple financial services. Enhancing their effectiveness as risk management instruments, however, requires a minimum level of financial literacy. The framework and examples also highlight (3) the importance of public policies, in particular for prevention, also to support human rights; also the market-emulating role of many public instruments.

\section{How the World Bank uses SRM}

The Bank has used the SRM framework to reassess and improve the design of a number of traditional social protection activities and programmes. For example, SRM has been applied in the area of labour markets and job creation to understand better the complementarities as well as substitutability between labour market regulation and income support systems. Both help individuals manage risk, although with different effects on job creation and destruction and thus on overall levels of employment. Informed by recent empirical analyses, there is increasing focus on promoting policies that protect incomes but not the job itself, i.e. 'flexicurity' as a better strategy for sustainable job creation (World Bank 2004; Vodopivec 2004).

In the specific area of income support, new thinking on risk and behaviour has improved our understanding of why it has been difficult to expand coverage of old-age pension schemes in low-income settings, even when the systems seem well designed (Holzmann and Hinz 2005). Analysis suggests that individuals who face large and immediate risks and lack effective instruments to manage them are less willing to participate in schemes designed to manage distant risks, i.e. becoming old without adequate resources. Put differently, annuitisation of assets to deal with the uncertainty of death becomes less attractive when the markets for other risks are themselves less complete.

The SRM framework has also helped the Bank revisit and expand the role of social safety nets from a narrow instrument of equity to one that addresses both equity and efficiency concerns. Conditional or unconditional transfers that help keep children in school, contribute to sustained good nutrition, or help poor households avoid selling productive assets after a shock, have large and important ramifications for poverty reduction (Grosh et al. 2007).

More generally, the framework has been useful for developing new approaches for addressing important risks in developing countries. Examples include the challenge of dealing with periodic droughts in Ethiopia and the move from emergency food aid to 'productive safety nets'; the introduction of an innovative transfer 
programme to respond to coffee price shocks in Nicaragua; also the rapid response to natural disasters such as the Pakistan earthquake and the SE Asian tsunami - with cash transfer programmes and support for the disabled (Vakis 2006). SRM thinking has helped the Bank to experiment with innovative policies and programmes to address old and new risks, increasingly in partnership with other members of the aid community.

SRM plays an important, albeit still emerging, role in the Bank's strategic thinking about poverty reduction and development. It has helped us move from a backward-looking to a forward-looking concept of poverty, i.e. vulnerability to poverty. Work on income and poverty dynamics, made feasible by the increasing availability of panel data, has confirmed the conjecture that a substantial share of income (and consumption) poverty is transitory. Although measured poverty (the number of persons whose current welfare level lies below the poverty line) may be low at a particular point in time, many individuals hover near the poverty line and can be pushed below by uninsured risk and the lack of instruments to smooth income and consumption over time. Hence, focusing on vulnerability to poverty in policy design and implementation promises to deliver additional benefits for sustained poverty reduction and growth.

Last but not least, the SRM framework provides an additional rationale for dealing with vulnerable groups. Many of the most destitute, e.g. HIV/AIDS orphans, the disabled, widows raising young children, became destitute through a series of unfortunate (and poorly insured) shocks. Transfers can help to provide income support and basic needs for the most vulnerable. In addition, research is underway to identify more effective ex ante risk management instruments to help poor households manage risk and therefore avoid descending into extreme poverty or joining the ranks of vulnerable groups, with little chance of recovery.

\section{Work in progress}

Work on the SRM framework continues: it is, after all, a conceptual framework not a specific model of behaviour. As such, it proposes a way of thinking that can be filled in by different approaches of abstractions, empirical specification and testing. The future challenge, although not addressed here, lies in operationalising lessons derived from the framework and designing better policies.
One important ongoing area of work concerns how best to define and measure 'vulnerability', with the aim of assessing the effectiveness of risk management instruments in actually reducing vulnerability. At a very abstract level, vulnerability can be defined as the expected (large) utility loss due to risk. Attempts have been made to operationalise the concept so that it can be used for policy work in developing countries, for instance through the use of income or consumption variance, money-metric measures of utility, or assessing 'vulnerability to poverty' (Holzmann et al. 2003). Vulnerability to poverty is defined in terms of probabilities, i.e. an individual is vulnerable to poverty if the probability of falling below an agreed poverty line (y) over the next $t$ periods is sufficiently large (greater than $x$ ). While intuitively appealing, calculating measures of vulnerability to poverty is analytically challenging and very data intensive. Hence the quest continues.

New thinking is also underway regarding the role of 'redundancy' or back-up plans in risk management, especially for the poor. The hypothesis is that individuals are particularly vulnerable if they lack a second or third line of defence against risks, given that the first may not be adequate. But back-up plans consume resources and hence become less attractive the higher the opportunity costs/lower the income. On the other hand, providing good back-up measures, e.g. government transfer programmes of last resort, may reduce incentives to develop good front-line SRM instruments, including a greater role for the private sector. Is this empirically relevant? We do not yet know.

Research is also underway on the links between uninsured risk, shocks and extreme poverty, with the aim of designing social protection programmes that help poor households manage risk ex ante, and thus avoid descending into extreme poverty. This work broadens the nexus of thinking on vulnerable groups to better address behavioural responses to risk.

Last but not least, there is a growing body of new thinking and analytic work on the links between risk and growth, with strong implications for development and poverty reduction in low-income settings. In a more evolutionary view of economic development, exposure to risk in the context of incomplete risk markets may have a positive impact on growth, to the extent that it leads to special efforts on the part of individuals to cope with 
shocks. On the other hand, under-insured risk could instead lead to losses in human capital or the use of less effective (albeit less risky) production technologies. The first effect could lead to innovation and new production technologies, and hence support progress toward advanced economies. The latter may support the use of existing technologies or safeguarding of human capital, and hence be more relevant for developing economies. But hypotheses in this area are well ahead of our empirical understanding, and hence of our ability to offer good policy advice on how best to deal with risk in the context of economic growth.

\section{Concluding remarks}

SRM has provided an important and forward-looking conceptual framework to advance new thinking around social protection activities. It has helped the World Bank move from a traditional, instrumentbased definition of social protection, to a more objective-based definition that encompasses a diverse set of informal, market-based and public programmes. Moreover, SRM has helped in

\section{Note}

1 A forthcoming volume, Incorporating Risk into Poverty Analysis: Progress and Challenges (Chouduri et al.), summarises both the academic and policy literatures. There is a substantial body of work on

\section{References}

Chouduri, S., Datt, G., Kozel, V., Vakis, R. and Badiani, R. (forthcoming) Incorporating Risk into Poverty Analysis: Progress and Challenges

Dercon, S. (2005) Risk, Growth, and Poverty; What do we Know, What do we Need to Know? Department of Economics, Oxford: Oxford University

Grosh, M., Blomquist, J., Del Ninno, C., Milazzo, A., Ouerghi, A., Tesliuc, E. and Wiegand, C. (2007) From Protection to Promotion: The Design and Implementation of Effective Safety Nets, Washington DC: World Bank

Holzmann, R. (1990) 'The Welfare Effects of Public Expenditure Programmes Reconsidered', IMF Staff Papers 37: 338-59

Holzmann, R. and Hinz, R. (2005) Old-Age Income Support in the 21st Century: An International Perspective on Pension Systems and Reform, Washington DC: World Bank expanding not only the objectives but also the effects of Bank-supported programmes, from addressing only equity concerns and redistribution to new work on improved efficiency and economic growth. Anchoring the framework in second-best considerations has been instrumental in overcoming typical equity-efficiency trade-offs: it is feasible and indeed desirable to address both. As a result, the support of SRM instruments for all is fully consistent with a human rights-based approach and the call for minimum provisions. Whether this should happen through universal access, means-tested provisions, or selective conditionalities for the poor, is still open for discussion. Encouragingly, the SRM framework is being used increasingly outside the World Bank and its application has made more than a few flowers bloom. SRM has withstood the test of time and has indeed flourished. It has proved useful for the review and (re)design of traditional programmes, and has been inspirational for the development of new interventions. While its refinement and application remain a work in progress, SRM promises to deliver real progress for development.

risk in agriculture, also a number of recent studies on the impacts of terms-of-trade and macroeconomic shocks, conflicts and civil unrest, health shocks and HIV/AIDS and a growing literature on the impacts of natural disasters.

Holzmann, R., Sherburn-Benz, L. and Tesliuc, E. (2003) Social Risk Management: The World Bank's Approach to Social Protection in a Globalizing World, Washington DC: World Bank

Vakis, R. (2006) 'Complementing Natural Disasters Management: The Role of Social Protection', Social Protection Discussion Paper 0543, Washington DC: World Bank

Vodopivec, M. (2004) Income Support for the Unemployed: Issues and Options, Regional and Sectoral Studies, Washington DC: World Bank

World Bank (2007) Sector Strategy Implementation Update, Washington DC: World Bank

World Bank (2004) World Bank Development Report 2005 - A Better Investment Climate for Everybody, Washington DC: World Bank

World Bank (2001) Social Protection Strategy: From Safety Net to Springboard, Washington DC: World Bank 